\title{
Wound healing activities of Moringa oleifera leaves extract cultivated in Kurdistan region-Iraq
}

\author{
Shang A. Tofiq ${ }^{1}$, Hoshayr A. Azeez ${ }^{2, *}$ and Hemn Hassan Othman ${ }^{2}$ \\ ${ }^{1}$ Department of Biology, College of Science, University of Sulaimani, Sulaimania-Iraq; ${ }^{2}$ College of Pharmacy, University of Sulaimani, \\ Sulaimania -Iraq
}

Received: June 14, 2020; Revised: September 7, 2020; Accepted: Oct 13, 2020

\begin{abstract}
Medicinal plants have been used for many years as an ancient curative method for treating and healing wounds in different cultures. Therefore, and accordingly this work has been conducted to study wound healing activity of Moringa oleifera leaves extract cultivated in the Kurdistan region in the northern Iraq (KRG). In the current investigation, experimentally-induced wounds in rats have been infected with strains of Staphylococcus aureus and Pseudomonas aeruginosa clinically isolated from the wound site in hospitalized patients. High Performance Liquid Chromatography (HPLC) is used to determine some bioactive compounds within the extract. Plant leaf was extracted by using the maceration method and 70\% ethanol as solvent. The HPLC results were dependent on comparison between the extract with standards. Two lacerated wounds were made on each animal at either side of the thoracolumbar spine and inoculated by a $0.4 \mathrm{ml}$ bacterial suspension. The treatment regimen was for 14 days with different formulation of ethanolic leaves extract, and gentamicin ointment as a control positive. At the end point of the experimental trial, animals were euthanized humanly at day 15. Samples from healed-wounded skin was prepared for histological evaluation. Generally speaking, our findings indicated that alcoholic leaf extract showed potential wound healing property in different concentration as a dose-dependent manner of the extracted ointment $3.5 \%, 5 \%, 10 \%$ particularly $10 \%$ of the extract formulation which showed better results in comparison to gentamicin ointment. The presented essential constituents for Moringa leaf derivatives were gallic acid (3461 ppm), catechin (1201 ppm), rutin (286 ppm) and quercetin (88 ppm). Last but not least, the extract was able to provide promising evidence to possess a drug formulation material.
\end{abstract}

Keywords: Moringa oleifera, leaves extract, Bioactive compounds, HPLC, Wound healing.

\section{Introduction}

The largest organ of the body is skin which acts as a barrier against external means. The loss of skin tissue integrity, as in the development of wound, can cause lesions or illnesses (Sussman and Bates, 2007). Disturbance of the cellular and anatomic progression of a tissue defined as the wound with or without microbial infection is happening due to cut with sharp-edged things or any accident (Sabale et al., 2012). It may occur due to chemical, immunological, physical and microbiological attacks to the tissue, leading to cellular disruption of tissue is occurring. Healing of wound is a procedure in which tissue regeneration occurs (Alam et al., 2012). Wound healing is a natural circumstance by which the body itself replacing normal structure functions and gets over the damage to the tissue. The skin wound healing process includes progress in different phases such as hemostasis, inflammatory, proliferative and remodeling (Eming et al., 2014). Natural sources of biologically active compounds were medicinal plants (Ji et al., 2009; Zhang and Ma, 2018). Some of these biologically active compounds have advantageous effects, which can be used to enhance human health (Mohammed and Manan, 2015). The usage of medicinal plants as an alternative to chemically synthesized drugs within the treatment of diseases has been accepted worldwide (Liew and Yong, 2016; Khdhir et al., 2019). Many medicinal plants are monitored for powerful, newer and low-cost wound-healing agents (Boakye et al., 2018). Any plants characterized and proved to be antioxidant, antimicrobial and antiproliferative can be used in the wound treatment as an ointment delivery system (Arun et al., 2016). Plants were used for this purpose, such as Aloe vera, $M$. oleifera, and Kigelia Africana, green tea, Echinacea, grapevine, ginseng, chamomile, rosemary (Pazyar et al., 2014). M. oleifera is a plant that belongs to the family Moringaceae. It is commonly known as the drumstick tree or horseradish tree and is native to India but grown in different parts of the world. M. oleifera can be characterized by its nutritional values and medical uses. The plant of Moringa includes various components, which are quercetin, kaempferol, vitamins, carotenoids, B-sitosterol, caffeoylquinic acid, zeatin, tannin, flavonoids, alkaloids, polyphenol, phenolic acid, oxalates, isothiocyanates saponins, glucosinolates and phytates (Anwar et al., 2007; Tahir et al., 2020). Different methods to separation of these bioactive compounds such as high-performance liquid chromatography (HPLC) is a tool to determine qualitative

\footnotetext{
* Corresponding author e-mail: hoshyar.azeez@univsul.edu.iq.
} 
and quantitative analysis of bioactive constituents such as phenol and flavonoids in the different plant parts (Nouman et al., 2016, Maqsood et al., 2017). Traditionally, leafpaste of $M$. oleifera has been applied to infected wounds and treatment of sore eyes by traditional healers and has been shown to be successful (Rathi et al., 2006). Many studies have shown that the leaf, flower, bark, root, seed, and nearly all of $M$. oleifera plants exhibit antimicrobial activity including antibacterial, antifungal, antiviral and antiparasitic activity. Many medicinal uses were also reported, which include anti-inflammatory, antihypertensive, antioxidant, hepatoprotective, anti-diabetic, anticancer, analgesic activity, cholesterol-lowering activity, cardiac and circulatory stimulant (Nweze and Nawfor,2014; Mbosso et al.,2014; Rani et al., 2018).

$M$. oleifera leaves cultivated in Kurdistan region (KRG) of Iraq have never been screened for wound healing activity in Kurdistan region. Therefore, the objectives of this study are to determine the healing properties of $M$. oleifera extract on an infected wound in male wistar albino rats and to identify some bioactive compounds present in leaves using HPLC method.

\section{Materials and Methods}

\subsection{Plant collection and identification}

Leaves of $M$. oleifera were collected from Baranan mountain when cultivated for the first time in KRG-Iraq. The Baranan mountain has rocky slopes and valleys. The Moringa plantations are situated [latitude: $35.18279^{\circ} \mathrm{N}$, longitude: $45.65111^{\circ} \mathrm{E}$ and altitude: 879.1 masl. Annual rainfall: $450-700 \mathrm{~mm}$, temperatures ranged from $-5^{\circ} \mathrm{C}$ to $45^{\circ} \mathrm{C}$ ] (Tahir et al., 2018). The plant was authenticated by the plant taxonomist Assistant Prof. Dr. Karzan O. Qadir at Biology Dept., College of Science /University of Sulaimani. The collected aerial parts were air-dried then ground into powder using a mechanical grinder (GEEPAS) and packed into an ice-packed plastic container for further use.

\subsubsection{Plant extraction}

Fifty grams of collected powdered form of leaves weighed and extracted with $1000 \mathrm{ml}$ of $70 \%$ ethanol by maceration, using shaker incubator (Daihan LABTECH) for $72 \mathrm{hrs}$ at $40^{\circ} \mathrm{C}$. The extract solution was filtered by using filter paper (Whatman No.1) and the filtrate concentrated at $45^{\circ} \mathrm{C}$ by rotary evaporator (Heidolph); finally, the resulting extracts were freeze-dried by lyophilizer (Alpha 1-2 4Dplus) and the resultant crude powder was kept at -20 until use (Vongsak et al., 2013).

\section{2. . Phytochemical analysis with the HPLC method}

An amount of $0.5 \mathrm{~g}$ of plant powder was extracted with $10 \mathrm{ml}$ of methanol (HPLC grade) for $1 \mathrm{~h}$ on a magnetic stirrer. The extract was achieved at room temperature and kept from light. After filtering the extract, the residue was re-extracted with the same volume of methanol, then both of the filtrates were mixed and evaporated to dryness. After that, it was dissolved in $5 \mathrm{ml}$ methanol (HPLC grade) to a final $1 \%$ concentration. Next, it was filtered using $0.45 \mu \mathrm{m}$ membrane filters. Finally, the samples were stored at $4{ }^{\circ} \mathrm{C}$, aiming bioactive compound identification (Azeez et al., 2017). Different concentrations of standards were used, 15ppm of gallic acid, rutin, catechin and 10ppm of quercetin.

\subsection{Isolation and identification of bacterial isolates}

Clinical isolates of $S$. aureus and $P$. aeruginosa were isolated from swab samples from wound infection in patients attending Shar Hospital. The isolates were identified using Gram staining, microbiological analysis using differential media (Mannitol Salt Agar, Cetrimide Agar) and Biochemical tests (VITEC2).

\subsection{Experimental design}

The healthy adult male Wistar albino rats of about 200$300 \mathrm{~g}$ body weight were used; Animals were attained from Department of Biology, College of Education, University of Sulaimani; they were housed in a controlled environment that was a 12 hours' light/dark cycle, with a temperature of $\left(23 \pm 5^{\circ} \mathrm{C}\right)$, and the rats were supplied with tap water and food ad libitum. The handling of animals and all of the experiments were carried out following the institutional guidelines and the Ethical Committee for Animal Research of Sulaimani University. The rats were housed individually in individual polyethylene cages kept one week before the experiment for adaptation. The rats were fasted overnight and then anesthetized as described by (Eyaref and Amid, 2010), with an intraperitoneal injection of $5 \%$ ketamine $(35.0 \mathrm{mg} / \mathrm{kg})$ and $2 \%$ xylazine $(5.0 \mathrm{mg} / \mathrm{kg})$. Two laceration wounds (3 cm long, $1 \mathrm{~cm}$ deep) made on either side of the thoracolumbar spine of each rat were discussed by (Moscati et al., 1998). The dorsal hair of rats was shaved by an electric shaver and the surface was cleaned with antiseptic. Bleeding was restricted by using sterile gauze pressure. Following laceration, wounds were inoculated with $(0.4 \mathrm{ml}$ of inoculum for each $S$. aureus and $p$. aeruginosa) standardized inoculum by spectrophotometer $\left(10^{8}\right.$ $\mathrm{CFU} / \mathrm{mL}$ ), let to not spread for $30 \mathrm{~min}$.

The experimental rats were randomly divided into 7 groups with 6 animals per each group:

G1: wound without infection and treatment.

G2: infected wound without treatment.

G3: infected wound treated with Vaseline.

G4: infected wound treated with Gentamicin ointment.

G5: infected wound treated with $M$. oleifera leaf ethanolic extract in $3.5 \%$ ointment base.

G6: infected wound treated with $M$. oleifera leaf ethanolic extract in 5\% ointment base.

G7: infected wound treated with $M$. oleifera leaf ethanolic extract in $10 \%$ ointment base.

\subsection{Ointment preparation}

For preparing extract formulations, 1.75g (3.5\%), 2.5g (5\%), $5 \mathrm{~g}(10 \%)$ of the extract mixed with $48.25 \mathrm{~g}, 47.5 \mathrm{~g}$, $45 \mathrm{~g}$ white Vaseline, respectively. All ingredients of leaves extract ointment were mixed in the mortar and stirring constantly until homogenous and form an ointment preparation, and put in a clean container for topical application during the experiment (Laut et al., 2019).

\subsubsection{Treatment schedule}

An amount of each of extract ointment, Gentamicin ointment as standard ointment and Vaseline was put in wounds once per day to treat different groups of animals for 14 days. 


\subsection{Histopathological Assessment}

At day 15 of the experiment, the rats were slaughtered, tissue sections were taken from healed wounded skin for all rats, placed in $10 \%$ neutral buffered formalin solution for optimum fixation at the minimum 24hrs, at room temperature. Following fixation, the specimens were gradually dehydrated by using the ascending percentage of ethanol solution $(60,80,90$, and $98 \%, v / v)$, then cleared in xylene and embedded in paraffin. Histopathological tissue sections of $5 \mu \mathrm{m}$ thickness were obtained and standard Hematoxylin and Eosin techniques were used for staining, and finally mounted on a glass slide then visualized under the light microscope (Prisacaru et al., 2013).

\subsubsection{Semi-quantitative histopathological evaluation}

As a quantitative measure, histological sections of skin wounds from each animal were estimated and measured in $\mu \mathrm{m}$ and statistically evaluated as a mean percentage. While inflammatory cells were counted in a randomly chosen 10 fields tissue sections under high power magnification (100X), then the mean average was calculated statistically in percentage. Moreover, the area of granulation tissue formation, proliferated collagen fibers and epidermal thickness was measured in $\mu \mathrm{m}$, and semi quantitatively evaluated in the same manner as inflammatory cells. Tissue samples were analyzed under the light microscope by the mean of image analyzer software (AmScope Ver. 3.7) using a digital microscope camera (MU300). The mean percentage of calculated values were estimated as following lesion scores (score $>75 \%$ as mild lesion; score $50-75 \%$ as moderate lesion; score $<50 \%$ as a severe lesion) (Aziz et al., 2020).

\subsection{Statistical analysis}

Statistical analyses were conducted with SPSS20 (USA) software. Differences between groups were evaluated by ANOVA followed by Tukey post hoc test.

\section{Results}

\subsection{Phytochemical analysis with the HPLC method}

The results of qualitative and quantitative estimation of some bioactive compounds in the crude ethanolic extract of $M$. oleifera leaves by using HPLC assay "which is for the first time estimated in Kurdistan Region" indicated the presence of gallic acid, rutin, quercetin and catechin based on the retention time of the extract with different standards as represented in (Table 1); different concentrations of the compounds were used.

(Figure 1, 2, 3, 4) HPLC analysis of different standards: gallic acids, rutin, quercetin and catechin respectively, with (Figure 5) HPLC chromatogram of the ethanolic extract of $M$. oleifera.

Quantity of each compound was shown in (Figure 6): gallic acid (3461 ppm), rutin (286 ppm) and quercetin (88 ppm) and catechin (1201 ppm).
Table 1. Retention time, area and concentration of standards.

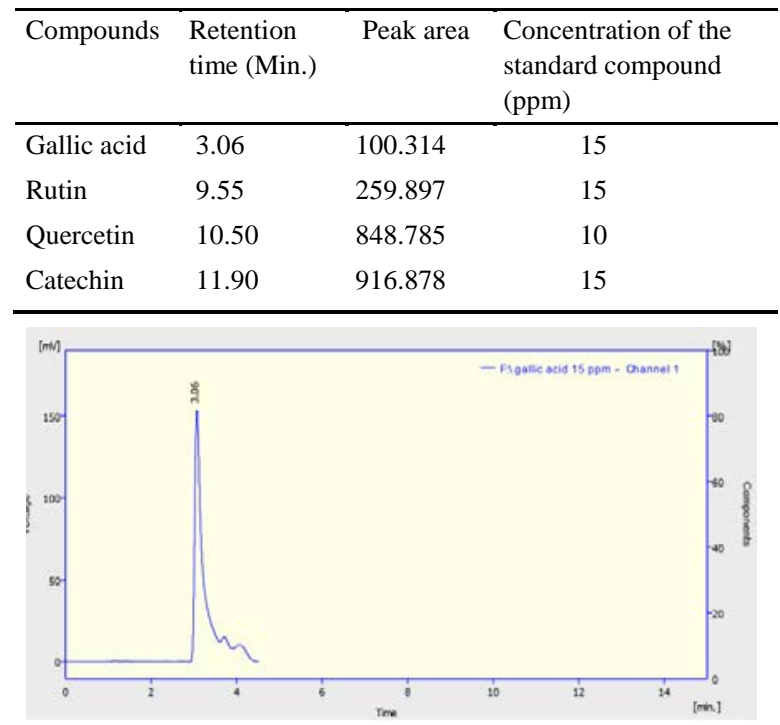

Figure 1. HPLC analysis for gallic acid standard.

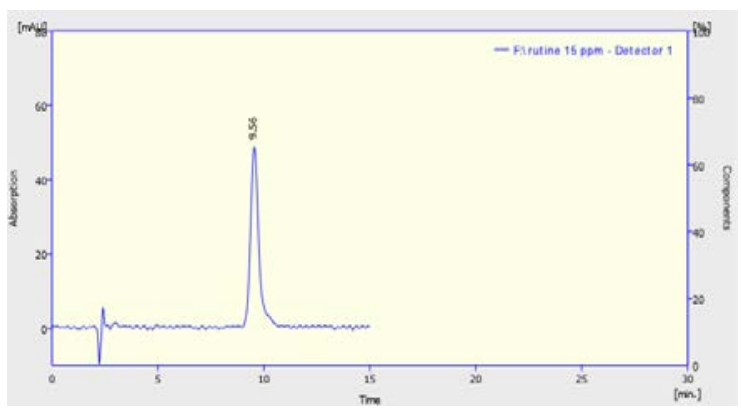

Figure 2. HPLC analysis for rutin standard.

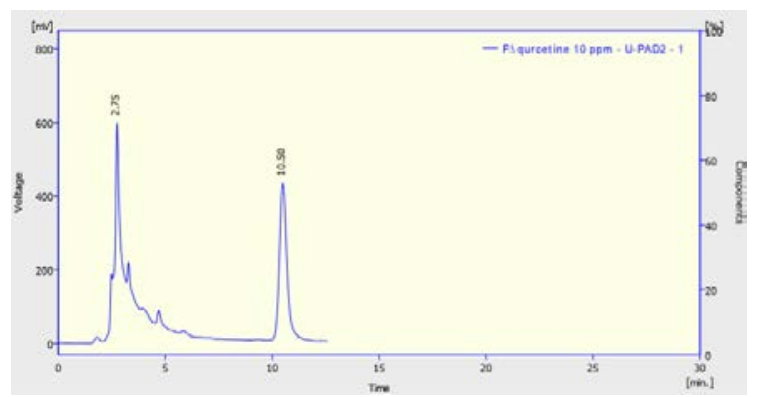

Figure 3. HPLC analysis for quercetin standard.

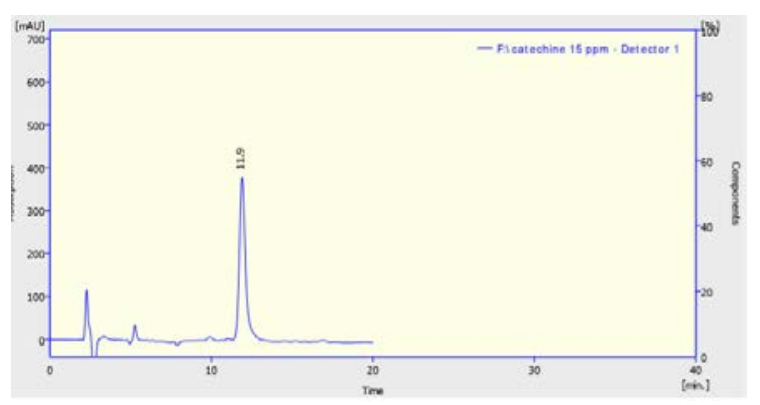

Figure 4. HPLC analysis for catechin standard. 


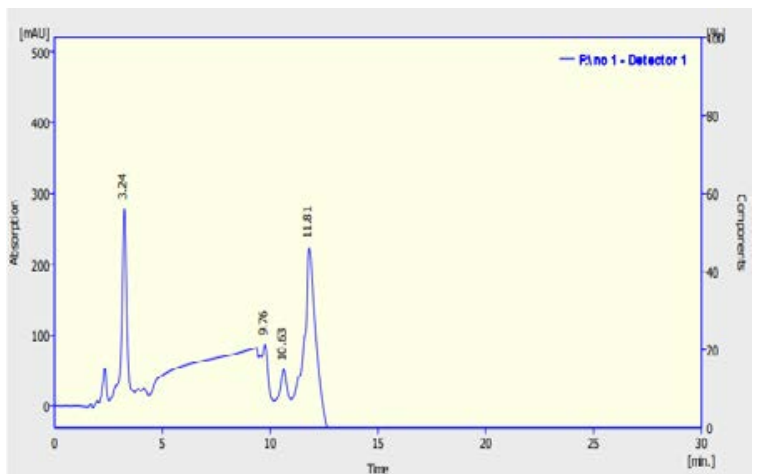

Figure 5. HPLC chromatogram of $M$. oleifera leaf extract.

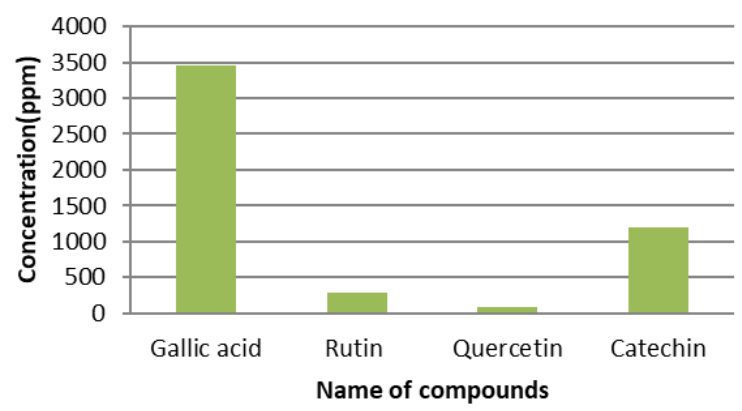

Figure 6. Concentration of some bioactive compounds accumulated in leaves of $M$. oleifera.

\subsection{Wound healing property of M. oleifera}

Histopathological features of lacerated animal skin were represented in (Figure 7) group1; after 14 days of laceration, the untreated wound showed individual variation. This figure shows diffuse dissemination of losing granulation tissue (GT), which is interlaced with newly formed blood vessels (BV). The section (upper left) shows necrotic debris at the skin surface mixed with inflammatory cells and dispersion of pink amorphous ground substances. While the upper right section displays vast proliferation of thicker granulation tissue (GT) perpendicular to the newly formed blood vessels and reepithelialization of the epidermis (EP). This variation in healing may be due to the different immune response amongst the individuals and/or the animals may be already were infected. Group2a, which represents the infection by gram-positive bacteria $S$. aureus without treatment, indicates the formation of a significant amount of granulation tissue (GT) at the dermal layer with the presence of some giant cells, and newly formed blood vessels can also be seen. The section shows a considerable amount of necrotic debris at the epidermal layer. When compared with group2b (which represents infection by gram-negative bacteria $p$. aeruginosa without treatment), it shows a remarkable amount of fibrinous inflammatory exudate (IE) mixed with many inflammatory cells and bacterial colonies. Besides, the section reveals the deposition of a significant amount of proteinous ground substances in the dermis (GS). The section also shows the presence of many hair follicles (HF). Examination of (Figure 8) group3a, gram-positive, vaseline treated group reveal a significant loss (GT) formation, with an obvious longitudinal section of newly formed blood vessels and some (HF). The section (group3a) shows extended collagen bundles (CB), in addition the section showed epidermal tissue (ET) which were thicker than group3b.
Whereas, the group3b (gram-negative vaseline treated group) showed substantial proliferation of thick collagenous (GT). The area displays pinkish randomly running collagen fibers (CF). In addition, the section shows many (HF) and sebaceous glands. It may occur because of contraction of elastic fibers, more collagen fibers and elastic fibers were formed; it causes wound contract, nearing the wound edge, pulls hair follicles and sebaceous gland from surrounding wound skin into near the wounded area. Whereas group4a, gram-positive, gentamicin $0.1 \%$ ointment shows the considerable formation of (GT) together with perpendicular newly formed (BV). The section (group4a) shows some area of (HF) and significant regeneration of epidermal layer which is more than in group4b. The group4b (gram-negative, gentamicin $0.1 \%$ group) reveal significant development of (GT) at the wound area, assorted with clear deposition of pinkish (GS), together with the apparent formation of new blood vessels with proliferated (CF). Gentamicin ointment accelerates or stimulates wound healing through the formation of perpendicular blood vessels, regeneration of hair follicles and epidermal layer. Groups in (Figure 9) group5a, group6a and group7a, gram-positive, 3.5\%, 5\%, $10 \%$ plant extract formulation treated group respectively, appeared to heal better than the controls based on gross examination and histopathological evaluation. The wounds in all extract-treated groups showed significant formation and distribution of (GT), newly regenerated sebaceous gland and (HF) and excessive amount of collagen fibers and mature epidermis with a well-formed keratin layer, there was no noticeable necrosis or inflammation. (Figure 9) group5b, group6b and group $7 b$ which represent infected lacerated wound with gram-negative bacteria $P$. aeruginosa treated by $3.5 \%, 5 \%, 10 \%$ plant extract formulation, respectively. These sections demonstrate diffuse and proliferation of (GT) together with the proliferation of (CF) and significant amount of (GS) as well as many regenerated (HF). Excellent reepithelialization indicated by re-establishment of the epithelial continuity in the form of a mature epidermis with a well-formed keratin layer were also shown. From this preliminary study, it can be illustrated that the rats infected by gram positive bacteria and treated with different formulation of plant extract possess better and moderate wound healing comparing to the vaseline and gentamicin treated group. Moreover, among plant extract treated groups, $10 \%$ extract treated group show better wound healing represented by less scarring, brighter skin, many regenerated hair follicles and sebaceous gland in comparison to those treated with $5 \%$ and $3.5 \%$ of plant extract and gentamicin treated groups. However, it is important to acknowledge that these observations were only based on the microscopic level to the changes occured inside the wound which treated during fourteen days.

Table 2 represents the semi-quantitative measurement of wound healing properties of $M$. oleifera leaves. Since wound healing histological biomarkers show a significant increase in G1 control wound and other treatment groups including G3a, G4a and G7a which comprise vaseline, gentamicin and $10 \%$ plant extract formulation treatment group respectively, these treatment groups have been infected with gram-positive bacteria showing significant $\mathrm{P}<0.05$ increment in (GT) and (CF) proliferation as well as 
proper re-epithelialization. While wounds infected with both gram-positive (G2a) and gram-negative (G2b) bacteria and didn't receive any treatment (untreated infected wounds) shows unfortunate healing behavior in comparison with the rest treatment groups. On the other hand, other treatment groups for both gram-positive and gram-negative bacterial infection express moderate healing properties in comparison with G3a, G4a and G7a, which
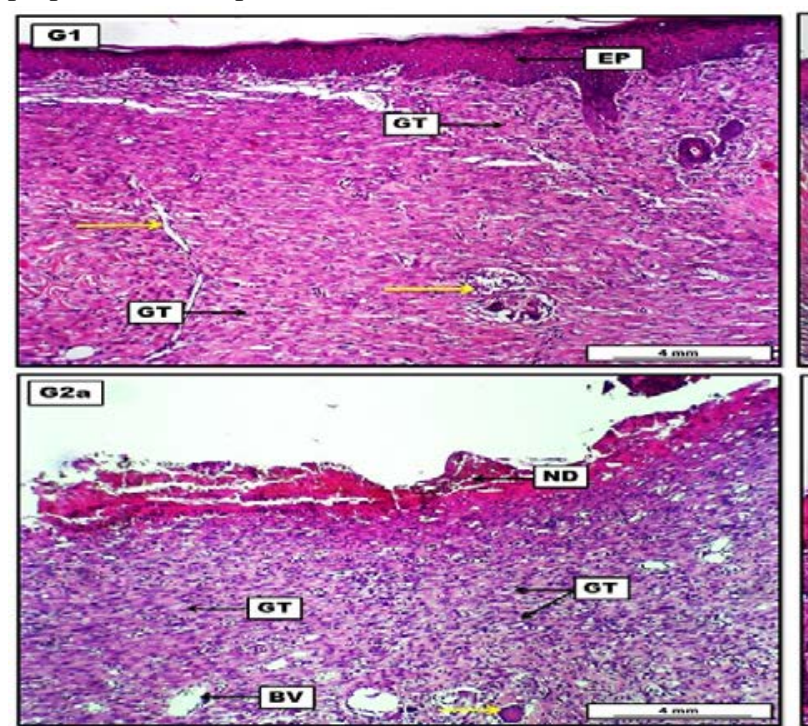

display significant healing performance among other groups. Thus, in conclusion, and according to lesion scoring shown in (Table 2), plant extract treatment groups show healing properties in all infected wounds, particularly in gram-positive groups in comparison to chemically synthesized ointment as positive control. However, it is in a dose-dependent manner.

Figure 7. Photomicrograph of skin from groups; (G1) wound untreated group shows diffuse dissemination of loose (GT), which is interlaced with newly formed (BV) and (yellow arrows). The section shows deep pink necrotic debris at the skin surface mixed with inflammatory cells (ND). Dispersion of pink amorphous ground substances (GS). The upper right section shows apparent epidermal regeneration (EP). (G2a) gram-positive, untreated group indicates the formation of (GT) at the dermal layer with the presence of some giant cells (yellow arrow). Newly formed (BV) can also be seen. The section shows a considerable amount of necrotic debris (ND). (G2b) gramnegative, untreated group demonstrates deposition of fibrinous inflammatory exudate (IE) mixed with many inflammatory cells and bacterial colonies (yellow arrows). In addition, the section reveals the deposition of pinkish pretentious (GS) in the dermis together with the presence of (ND). The section also shows the presence of many (HF). H\&E. Scale bars: $4 \mathrm{~mm}$
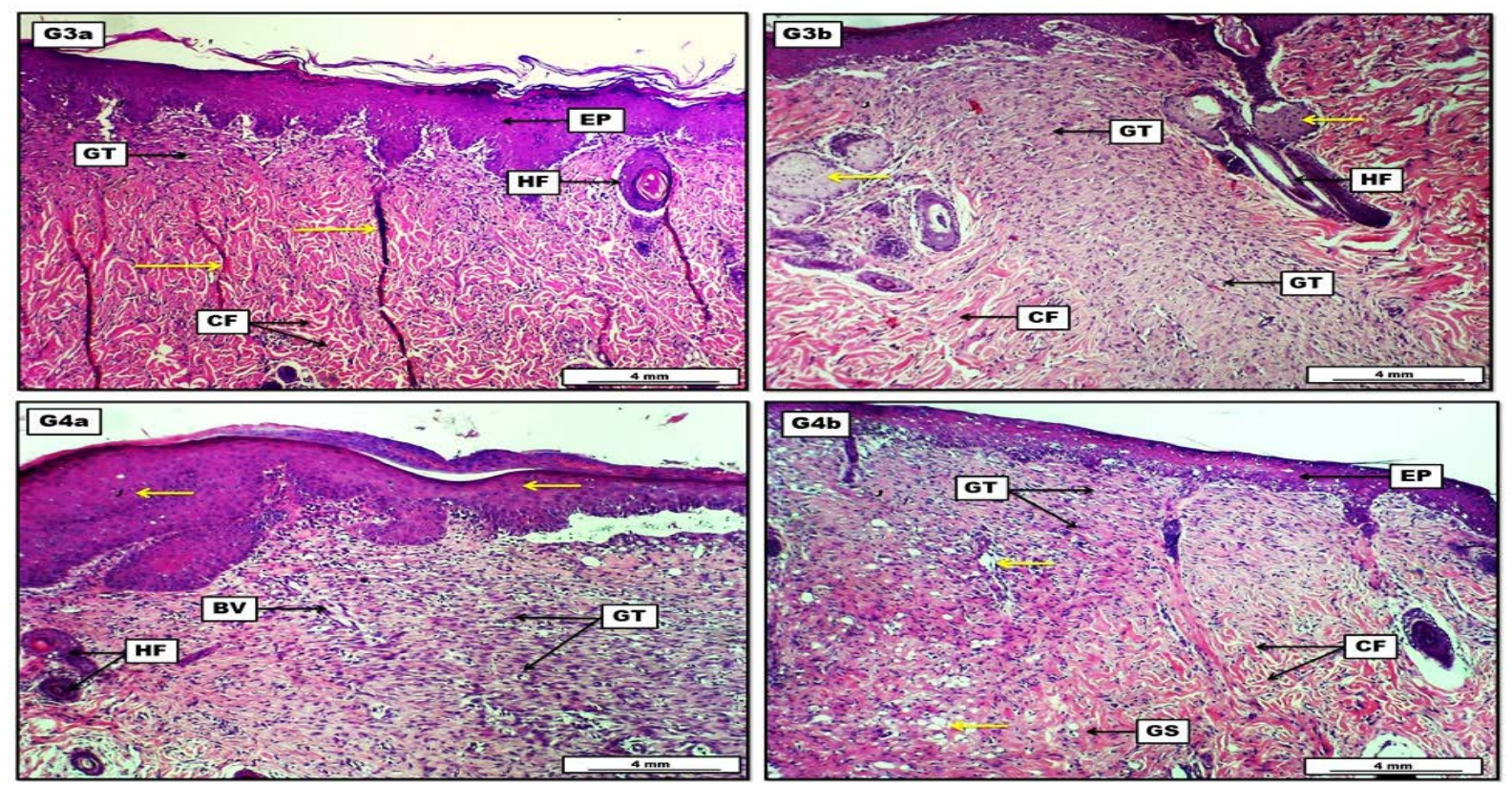

Figure 8. Photomicrograph of skin from groups; (G3a) gram-positive, vaseline group, reveals a significant loose (GT) formation, with an obvious longitudinal section of newly formed (BV)(yellow arrows). The section shows proliferated (CF), nearly thick epidermal layer (EP) and some (HF). (G3b) gram-negative, vaseline group, show proliferation of dense collagenous (GT). The area displays pinkish randomly running (CF). In addition, the section shows many (HF) and sebaceous glands (yellow arrows). (G4a) gram-positive, gentamicin treatment group, show formation of (GT) together with perpendicular newly formed (BV). Yellow arrows indicate significant regeneration of the epidermal layer. The area also shows some sections of (HF). (G4b) gram-negative, gentamicin treatment group, reveal the development of (GT) at the wound area, assorted with clear deposition of pinkish (GS), together with the apparent formation of new (BV) (yellow arrows) and proliferated (CF) along with the regenerative epithelial layer (EP). H\&E. Scale bars: $4 \mathrm{~mm}$. 

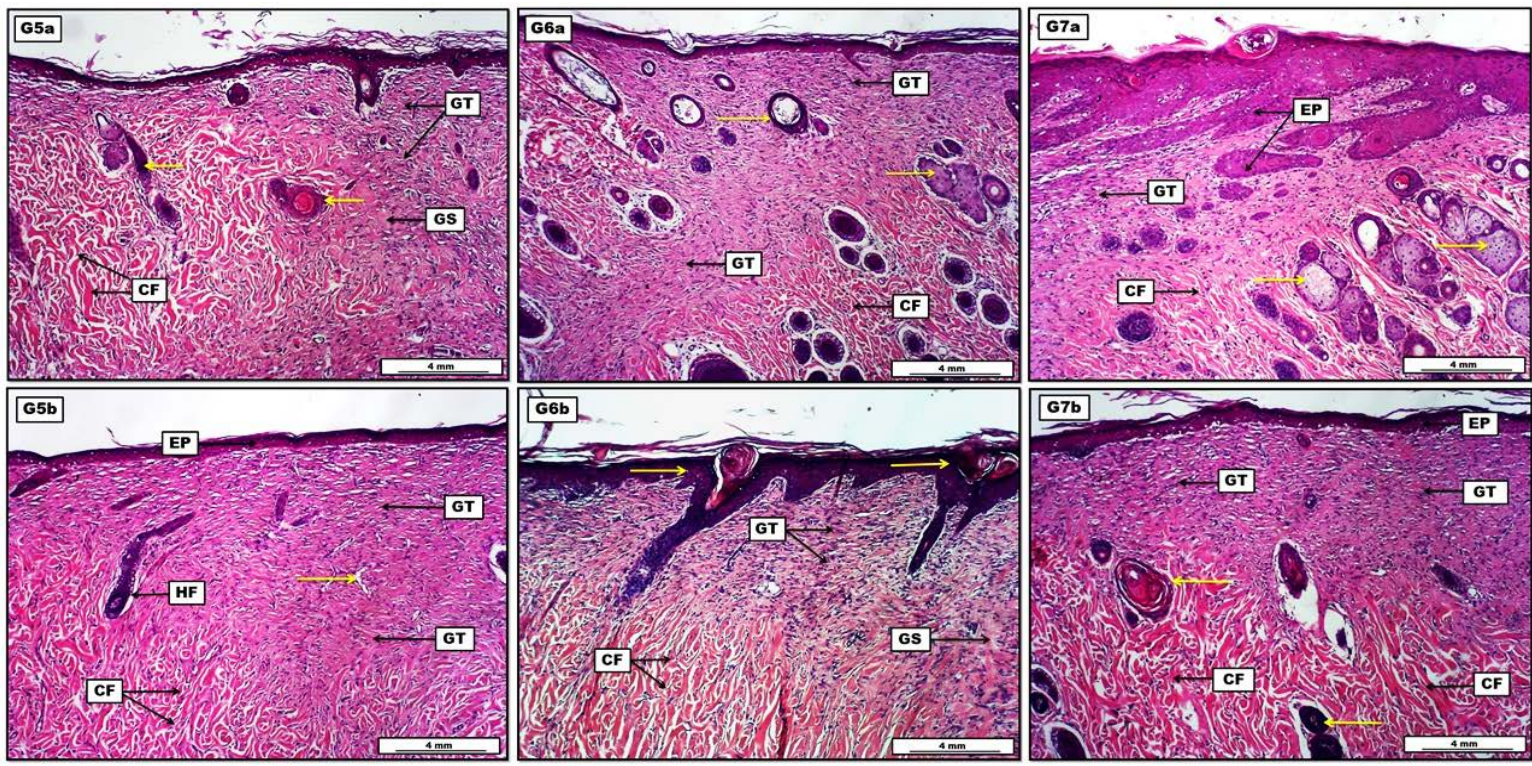

Figure 9. Photomicrograph of skin from groups; (G5a) gram-positive, 3.5\% plant extract treatment group, reveals prominent fibrous connective tissue proliferation and (GT) formation, Indicated by bundles of proliferated (CF). Marked deposition of eosinophilic (GS) in the dermis. The section shows the reformation of many (HF) (yellow arrows). (G5b) gram-negative, 3.5\% plant extract treatment group, displays formation and proliferation of (GT), in which extended and interlaced newly formed (BV) (yellow arrow). The proliferation of (CF) within the dermal layer, regeneration of some (HF) and the epidermis (EP) can also be seen. (G6a) gram-positive, 5\% plant extract treatment group, shows significant formation and distribution of (GT) extended deeply into the dermis, together with newly regenerated sebaceous glands and (HF) (yellow arrows). The section shows an excessive amount of proliferated (CF). (G6b) gram-negative, 5\% plant extract treatment group, demonstrates prominent (GT) formation together with the deposition of pinkish (GS). The section reveals the regenerative proliferation of (CF) and epidermal layers (yellow arrows). (G7a) gram-positive, 10\% plant extract treatment group, show distinct proliferation of (CF) interlacing with (GT) formation .Presence of many newly formed sebaceous glands and (HF)(yellow arrows). The section also shows excessive regeneration of epithelial tissue leading to the formation of many epidermal papillae (EP). (G7b) gramnegative, $10 \%$ plant extract treatment group, display significant (GT) formation together with the proliferation of large bundles of pinkish (CF) within the dermis. The section shows many regenerated (HF) distributed within the dermal layer (yellow arrows) along with the regenerative epidermal layer (EP). H\&E. Scale bars: $4 \mathrm{~mm}$.

Table 2. Histological quantitative evaluation of skin wound with different treatment values

\begin{tabular}{|c|c|c|c|c|c|c|}
\hline $\begin{array}{l}\text { Experimental } \\
\text { Groups } \\
\mathrm{N}=6\end{array}$ & $\begin{array}{l}\text { Granulation } \\
\text { Tissue Formation* } \\
\text { (Mean\%)** }\end{array}$ & $\begin{array}{l}\text { Inflammatory } \\
\text { Cells Infiltration } \\
\text { (Mean \%)** }\end{array}$ & $\begin{array}{l}\text { Collagen Fibers } \\
\text { Proliferation* } \\
\text { (Mean \%)** }\end{array}$ & $\begin{array}{l}\text { Skin Epidermal } \\
\text { regeneration* } \\
(\text { Mean \%)** }\end{array}$ & $\begin{array}{l}\text { Lesion } \\
\text { Scoring } \\
(0-100 \%)\end{array}$ & $\begin{array}{l}\text { Lesion } \\
\text { Grading }\end{array}$ \\
\hline (G1) CWG ${ }^{\dagger}$ & $78.9^{\mathrm{A}} \#$ & $64.1^{\mathrm{C}}$ & $73.7^{\mathrm{B}}$ & $61.7^{\mathrm{C}}$ & $60-100$ & Mild \\
\hline (G2a) G+ve WUG & $57.4^{\mathrm{C}}$ & $74.3^{\text {в }}$ & $58.5^{\mathrm{C}}$ & $44.8^{\mathrm{E}}$ & $40-75$ & Severe \\
\hline (G2b) G-ve WUG & $24.2^{\mathrm{E}}$ & $87.9^{\mathrm{A}}$ & $21.2^{\mathrm{E}}$ & $28.2^{\mathrm{E}}$ & $20-75$ & Severe \\
\hline (G3a) G+ve + VTG & $84.6^{\mathrm{A}}$ & $77.5^{\mathrm{A}}$ & $85.1^{\mathrm{A}}$ & $71.4^{\text {в }}$ & $70-100$ & Mild \\
\hline (G3b) G-ve + VTG & $65.4^{\mathrm{C}}$ & $73.6^{\mathrm{B}}$ & $68.2^{\text {в }}$ & $64.9^{\mathrm{C}}$ & $60-75$ & Moderate \\
\hline (G4a) G+ve + GTG & $79.2^{\mathrm{A}}$ & $70.6^{\text {в }}$ & $84.8^{\mathrm{A}}$ & $63.8^{\mathrm{C}}$ & $60-85$ & Mild \\
\hline (G4b) G-ve + GTG & $61.6^{\mathrm{C}}$ & $69.2^{\mathrm{B}}$ & $59.7^{\mathrm{C}}$ & $60.5^{\mathrm{C}}$ & $60-75$ & Moderate \\
\hline $\begin{array}{l}\text { (G5a) G+ve + } \\
3.5 \% \text { PETG }\end{array}$ & $60.7^{\mathrm{C}}$ & $64.8^{\mathrm{C}}$ & $61.8^{\mathrm{C}}$ & $68.3^{\text {в }}$ & $60-75$ & Moderate \\
\hline $\begin{array}{l}\text { (G5b) G-ve + } \\
3.5 \% \text { PETG }\end{array}$ & $54.2^{\mathrm{D}}$ & $69.4^{\mathrm{B}}$ & $53.9^{\mathrm{D}}$ & $59.4^{\mathrm{C}}$ & $50-75$ & Moderate \\
\hline $\begin{array}{l}\text { (G6a) G+ve + } \\
\text { 5\%PETG }\end{array}$ & $62.4^{\mathrm{C}}$ & $60.6^{\mathrm{C}}$ & $68.6^{\mathrm{B}}$ & $67.8^{\mathrm{B}}$ & $60-75$ & Moderate \\
\hline $\begin{array}{l}\text { (G6b) G-ve + } \\
5 \% \text { PETG }\end{array}$ & $60.7^{\mathrm{C}}$ & $67.9^{\text {в }}$ & $61.3^{\mathrm{C}}$ & $62.6^{\mathrm{C}}$ & $60-75$ & Moderate \\
\hline $\begin{array}{l}\text { (G7a) G+ve + } \\
\text { 10\%PETG }\end{array}$ & $74.3^{\text {в }}$ & $54.6^{\mathrm{D}}$ & $80.8^{\mathrm{A}}$ & $73.6^{\mathrm{B}}$ & $50-85$ & Mild \\
\hline $\begin{array}{l}\text { (G7b) G-ve + } \\
10 \% \text { PETG }\end{array}$ & $65.7^{\text {в }}$ & $60.3^{\mathrm{C}}$ & $72.6^{\mathrm{B}}$ & $68.4^{\text {в }}$ & $60-75$ & Moderate \\
\hline
\end{tabular}

Notes: *Area of granulation tissue formation, collagen fibers proliferation and skin epidermal regeneration were estimated in $(\mu \mathrm{m}) .{ }^{* *}$ Each value represents the mean percentage of $(n=6)$. \#Statistical comparison among groups: Mean values with different capital letters have significant differences at $(\mathrm{P}<0.05)$. †G1: Control wound group; G2a: Gram-positive and wound untreated group; G2b: Gram-negative and wound untreated group; G3a: Gram-positive and vaseline treatment group; G3b: Gram-negative and vaseline treatment group; G4a: Grampositive and gentamicin treatment group; G4b: Gram-negative and gentamicin treatment group; G5a: Gram-positive and 3.5\%plant extract treatment group; G5b: Gram-negative and 3.5\%plant extract treatment group; G6a: Gram-positive and 5\%plant extract treatment group; G6b: Gram-negative and 5\%plant extract treatment group; G7a: Gram-positive and 10\%plant extract treatment group; G7b: Gram-negative and $10 \%$ plant extract treatment group. 


\section{Discussion}

Owing to the occurrence of various secondary metabolites as alkaloids, tannins, glycosides and flavonoids, medicinal plants were lauded for their various pharmacological actions (Ali et al.,2008) (Pham et al.,2008). The current study determines the quality and quantity of some bioactive compounds in M. oleifera leaf by using HPLC method for the first time estimated in Kurdistan region. Determining of these compounds is correlated with the previous study which detected quercetin and rutin in methanolic extract of $M$. oleifera leaf (Khudaer et al., 2016). The presence of different phenolic acids such as Vanillic, Caffeic, Chlorogenic, Cinnamic, Coumaric, Ferulic, Syringic in the methanolic extract is inconsistent with our study in ethanolic extract; also, this study confirmed the presence of quercetin and rutin as our result (Al-shamma, 2014). Detection of gallic acid and quercetin is correlated with our study by (Niranjan et al., 2017). The presence of different phenolic compounds such as catechin, gallic acid, rutin and quercetin was detected by (Oboh et al., 2015). Moringa is a medicinal plant rich in phenols (gallic acid, p-coumaric acid and ferulic acid) flavonoids (Catechin, quercetin, kaempferol and niazimicin) (Tahir et al., 2020). Analysis of bioactive compounds by HPLC is affected by several factors, including purification of the sample, mobile phase, detectors and sorts of column (Katsube et al., 2004).

There are a number of wound contaminants which invade wound after occurring when it is exposed to external environments such as Escherichia coli, $S$. aureus and $P$. aeruginosa (Bowler et al., 2001). Wound healing is a complex and dynamic process in which the structure of cells and tissue layer of injured tissue are restoring into its natural state as carefully as possible. The healing process can be classified as a natural body mechanism to re-generating of epidermal and dermal tissues. It is clear that the rapidity of healing is directly related to providing suitable conditions of the damaged area to overcome the wound and the damage (Periyanayagam and Karthikeyan, 2013). Eventual agents to wound healing are plant products and mostly preferred due to their broad accessibility, non-toxicity, efficacy as crude preparations and little or lack of undesirable side effects (Kodati et al., 2011). The present investigation describes the wound healing activity of $M$. oleifera leaves; the crude extracts exhibited higher potency in infected rats with $S$. aureus and $P$. aeruginosa than the infected rats with no treatment and those treated by Vaseline and gentamicin ointment. Phytochemical analysis of $M$. oleifera indicated important classes of secondary metabolites that play an active role in wound healing and inhibition of microbial growth. Phytochemicals in $M$. oleifera which may speed up wound healing in rabbits (Kasolo et al., 2010). Topical application of M. oleifera leaves ethanolic extract in $3.5 \%, 5 \%$ and $10 \%$ ointment base stimulated wound healing in 14 days may due to the presence of flavonoids and phenols that may enhance vascularity, collagen synthesis promotes collagen cross linked (Kirubanadan and Bharathi, 2016). The result of this study is in agreement with the previous study which showed leaf ethyl acetate of $M$. oleifera extract had a potential therapeutic agent for healing wound through increasing wound closure rate and promote fibroblast proliferation examined histologically (Gothai et al., 2016). Topical use of ointment with $3.5 \%$ and $5 \%$ of the extract influenced rapid wound closure rate, leading to faster epithelialization, granulation tissue resolution, and maturation at histology (Coker et al., 2018). Other studies reported that $M$. oleifera leaves contain nitrogen containing naturally occurring compounds which are called alkaloids which make them capable to intercalate with microorganism's DNA, hence they have antimicrobial properties. Tannins and flavonoids have been investigated and had shown antioxidant activity that enhance wound healing. Therefore, the high antioxidant activity of Moringa genus mostly because of its higher concentration of flavonoids (Wang et al., 2017). Presence of high phenolic content in the extracts of different plants may be responsible for the free radical scavenging activity of the extracts (Devika et al., 2016). Phenolic compounds, specifically tannins, and flavonoids are familiar to antimicrobial effects and facilitate faster skin replacement. Quality of phenolic compounds, the interaction of these metabolites, and their quantities in an extract sometimes give a connection with activity since the bioactivity of the secondary metabolites, including phenolic compounds. In tissue healing processes and skin burns, phenolic protein complexes produce a film that prevent chemical damage and microbial infection as this film prevents dehydration and make a physical barrier to damaged tissue (Luseba et al., 2007). Daily application of antibiotic ointments, besides the antibacterial activity provides moisture to the scar to help boost scar products by rapid epithelialization. This explains better scar results in our gentamicin ointment treated group that shows more re-epithelialization, fibrous granulation tissue consisting of fibrous connective tissue and newly formed blood vessels, mature collagen bundles in the dermal connective tissue and healthy hair follicles. Ointment formulation containing ethanol leaf extract of cultivated $M$. oleifera demostrated better wound healing activity through reduced contraction rate and epithelialization period. Ethyl acetate fraction of $M$. oleifera was assessed in scratch assay and showed important constituents which effective in promoting cell proliferation and migration to close wound area (Gothai et al., 2016). Many polyphenolic compounds are able to reduce the expression of different pro-inflammatory cytokines, such as monocyte chemo attractant protein MCP-1, tumor necrosis factor TNF- $\alpha$, interleukin IL-1 $\beta$, IL-6, in many cell types (Comalada et al., 2006). Quercetin is one of the bioactive compounds analysed through HPLC method in the present study. It has anti-inflammatory mechanism by inhibition of the expression of proinflammatory cytokines in the mast cell and suppression of TNF- $\alpha$, thus, effect the wound healing (Pan et al., 2009). The use of the extract in ointment is more affective due to prolonged contact between extract with the wound area and it enhances the delivery of the extract to the wound site (Coker et al., 2018).

Finally, the present study suggested that ethanolic extract of $M$. oleifera leaves in different formulations promotes wound healing activity as the extract contains several bioactive compounds that possess an antiinflammatory effect improving effective wound healing. 


\section{Conclusion}

The current study confirms that leaves of $M$. oleifera cultivated in the Kurdistan region, Iraq, potentially exert wound healing activity in rats. It may be due to the presence of diverse bioactive compounds in different concentration such as gallic acid, rutin, quercetin and catechin. All these mixes are effective anti-inflammatory compounds which promote wound healing. Further studies to isolate and purified active compounds are needed to find the exact mechanism of $M$. oleifera leaves on wound healing.

\section{Acknowledgment}

The authors would like to express their utmost appreciation to the Department of Biology, College of Education, and the College of Pharmacy, University of Sulaimani for their support in providing many facilities such as laboratory animals, cages and animal house utilities with many other consumables to complete this project.

\section{Disclosure}

The authors report no conflicts of interest in this work.

\section{References}

Alam G, Singh M.P. and Singh A. 2011. Wound healing potential of some medicinal plants. Int. J. Pharm. Sci., 9(1):136-145.

Ali S.S, Kasoju N, Luthra A, Singh A, Sharanabasava H, Sahu A and Bora U. 2008. Indian medicinal herbs as sources of antioxidants. Int.Food Res. J., 41(1):1-15.

Al-Shammaa D.A.S. 2014. Phytochemical Investigation of the most important phenolic compounds in Moringa oleifera L. cultivated in Iraq. TIJ'S Journal of Science \& IT Management RJSITM., 3(8): 30-36.

Anwar F, Latif S, Ashraf M and Gilani A.H. 2007. Moringa oleifera: a food plant with multiple medicinal uses. Phytotherapy Research: Phytother Res [dnlm]., 21(1):17-25.

Arun M, Satish S and Anima P. 2016. Evaluation of wound healing, antioxidant and antimicrobial efficacy of Jasminum auriculatum Vahl. leaves. Avicenna J. Phytomed., 6(3):295.

Azeez H, Ibrahim K, Pop R, Pamfil D, Hârţa M and Bobiş O. 2017. Changes induced by gamma ray irradiation on biomass production and secondary metabolites accumulation in Hypericum triquetrifolium Turra callus cultures. Ind Crops Prod., 108:183189.

Aziz TA, Kareem AA, Othman HH and Ahmed ZA. 2020. The Anti-Inflammatory Effect of Different Doses of Aliskiren in Rat Models of Inflammation. Drug Des Devel Ther.,14: 2841.

Boakye YD, Agyare C, Ayande GP, Titiloye N, Asiamah EA and Danquah KO. 2018. Assessment of Wound-Healing Properties of Medicinal Plants: The Case of Phyllanthus muellerianus. Front Pharmacol., 9:945.

Bowler PG, Duerden BI and Armstrong DG. 2001. Wound microbiology and associated approaches to wound management. Clin. Microbiol. Rev., 14(2):244-269.

Coker M, Adejo G, Emikpe B and Oyebanji V. 2018. Evaluation of the wound healing potential of ointment preparation of ethylacetate extract of Moringa Oleifera (Lam) in rats. Afr $J$ Tradit Complement Altern Med., 15(3):64-71.
Comalada M, Ballester I, Bailon E, Sierra S, Xaus J, Gálvez J, de Medina FS and Zarzuelo A. 2006. Inhibition of pro-inflammatory markers in primary bone marrow-derived mouse macrophages by naturally occurring flavonoids: analysis of the structure-activity relationship. Biochem. Pharmacol., 72(8): 1010-1021.

Devika, M., Joshi, H. and Nalini, M.S., 2016. Phytochemicals, Antioxidative and in vivo Hepatoprotective Potentials of Litsea floribunda (BL.) Gamble (Lauraceae)-An Endemic Tree Species of the Southern Western Ghats, India. JJBS., 9(3):163-171.

Eming SA, Martin P and Tomic-Canic M. 2014. Wound repair and regeneration: mechanisms, signaling, and translation. Sci. Transl. Med, 6(265):265sr6.

Eyarefe OD and Amid SA. 2010. Small bowel wall response to enterotomy closure with polypropylene and polyglactin 910 using simple interrupted suture pattern in rats. J Anim Vet Adv., 2(3):7275.

Gothai S, Arulselvan P, Tan WS and Fakurazi S. 2016. Wound healing properties of ethyl acetate fraction of Moringa oleifera in normal human dermal fibro blasts. J. Intercult Ethnopharma col., 5(1):1-6.

.Ji HF, Li XJ and Zhang HY. 2009. Natural products and drug discovery. Can thousands of years of ancient medical knowledge lead us to new and powerful drug combinations in the fight against cancer and dementia? EMBO reports, 10(3):194-200.

Kasolo JN, Bimenya GS, Ojok L, Ochieng J and Ogwal-Okeng JW. 2010. Phytochemicals and uses of Moringa oleifera leaves in Ugandan rural communities. J. Med. Plant Res., 4(9): 753-757.

Katsube T, Tabata H, Ohta Y, Yamasaki Y, Anuurad E, Shiwaku $\mathrm{K}$ and Yamane Y, 2004. Screening for antioxidant activity in edible plant products: comparison of low-density lipoprotein oxidation assay, DPPH radical scavenging assay, and FolinCiocalteu assay. J. Agric. Food Chem., 52(8): 2391-2396

Khdhir JC, Ridha HH, and Azeez HA. 2019. Effect of Cherry Extract and Almond Oil on Oxonic cid-Induced Hyperuricemia in Male Albino Rats. ANJS., 22(4): 59-67.

Khudaer NB, Hassn ZYM, AL-Sammarrae KW and Ibrahim NK. 2016. Purification and Identification of Total Flavonoids Extracted from Moringa oleifera Leaves in Iraq. Res. J. Biotechnol., 10(2):73-80.

Kirubanadan S and Bharathi R. 2016. Histological and biochemical evaluation of wound regeneration potential of Terminalia chebula fruits. Asian J. Pharm. Clin. Res., 9:228-233.

Kodati DR, Burra S and Kumar GP. 2011. Evaluation of wound healing activity of methanolic root extract of Plumbago zeylanica L. in wistar albino rats. Asian J. Plant Sci., 1(2):26-34.

Laut M, Ndaong NA and Utami T. 2019. Cutaneous wound healing activity of herbal ointment containing the leaf extract of Acalypha indica L. on mice (Mus musculus). J. Phys. Conf. Ser., 1146: 012025.

Liew PM and Yong YK. 2016. Stachytarpheta jamaicensis (L.) Vahl: from traditional usage to pharmacological evidence. Evid Based Complement Alternat Med., Volume 2016, Article ID 7842340, 7 pages.

Luseba D, Elgorashi EE, Ntloedibe DT and Van Staden J. 2007. Antibacterial, anti-inflammatory and mutagenic effects of some medicinal plants used in South Africa for the treatment of wounds and retained placenta in livestock. S. Afr. J. Bot., 73(3):378-383.

Maqsood I, Tayyaba B, Najmi MH, Mazhar W, Bader Z, Janjua A and Sabah S. 2017. Pharmacokinetic study of atorvastatin after single dose administration among pakistani population. Pak Armed Forces Med., 67(4): 656-662.

Mbosso EJT, Ngouela S, Nguedia JCA, Beng VP, Rohmer M and Tsamo E. 2010. In vitro antimicrobial activity of extracts and compounds of some selected medicinal plants from Cameroon. J. Ethnopharmacol., 128(2):476-481. 
Mohammed S and Manan FA. 2015. Analysis of total phenolics, tannins and flavonoids from Moringa oleifera seed extract. J. Chem. Pharm. Res., 7(1): 135-7.

Moscati R, Mayrose J, Fincher L and Jehle D. 1998. Comparison of normal saline with tap water for wound irrigation. Am. J. Emerg. Med., 16(4):379-381.

Niranjan A, Ngpoore NK, Anis N, Kumar A, Lehri A, Shirke PA and Tewari SK. 2017. Simultaneous quantification of six phenolic compounds in various parts of Moringa oleifera Lam. using highperformance thin-layer chromatography. J.Plaanar Chromatogr. Mod.TLC., 30(6):502-509.

Nouman W, Anwar F, Gull T, Newton A, Rosa E and Domínguez-Perles R. 2016. Profiling of polyphenolics, nutrients and antioxidant potential of germplasm's leaves from seven cultivars of Moringa oleifera Lam. Ind Crops Prod., 83: 166-176.

Nweze NO and Nwafor FI. 2014. Phytochemical, proximate and mineral composition of leaf extracts of Moringa oleifera Lam. from Nsukka, South-Eastern Nigeria: JPBS., 9(1):99-103.

Oboh G, Ademiluyi AO, Ademosun AO, Olasehinde TA, Oyeleye SI, Boligon AA and Athayde ML. 2015. Phenolic extract from Moringa oleifera leaves inhibits key enzymes linked to erectile dysfunction and oxidative stress in rats' penile tissues Biochem. Res. Int., Volume 2015, Article ID 175950, 8 pages.

Pazyar N, Yaghoobi R, Rafiee E, Mehrabian A and Feily A. 2014 Skin wound healing and phytomedicine: a review. Skin Pharmacol Physiol ., 27(6):303-310.

Pan MH, Lai CS, Dushenkov S and Ho CT. 2009. .Modulation of inflammatory genes by natural dietary bioactive compounds. J. Agric. Food Chem., 57(11): 4467-4477..

Periyanayagam K and Karthikeyan V. 2013. Wound healing activity of the leaves of Artocarpus heterophyllus Lam .(Mora ceae) on ex-vivo porcine skin wound healing model. Innovare $J$. Life Sci., 1(1):28-33.

Pham-Huy LA, He H and Pham-Huy C. 2008. Free radicals, antioxidants in disease and health: Int J Biobed Sci., 4(2):89.
Prisacaru AI, Andritoiu CV, Andriescu C, Havarneanu EC, Popa M, Motoc AG and Sava A. 2013. Evaluation of the wound-healing effect of a novel Hypericum perforatum ointment in skin injury Rom J Morphol Embryol ., 54(4): 1053-1059.

Rani A, Zahirah N, Husain K and Kumolosasi E. 2018. Moringa genus: a review of phytochemistry and pharmacology. Front. Pharmacol., 9:108.

Rathi BS, Bodhankar SL and Baheti AM. 2006. Evaluation of aqueous leaves extract of Moringa oleifera Linn for wound healing in albino rats. Indian J. Exp. Biol., 44(11). 898-901.

Sabale P, Bhimani B, Prajapati C and Sabale V. 2012. An overview of medicinal plants as wound healers. J App Pharm Sci.., 2(11):143-150.

Sussman C and Bates-Jensen BM. 2007. Wound care: $a$ collaborative practice manual, third ed. Lippincott Williams \& Wilkins, Philadelphia.

Tahir NA, Qader KO, Azeez HA and Rashid JS. 2018. Inhibitory allelopathic effects of Moringa oleifera Lam plant extracts on wheat and Sinapis arvensis L. Allelopathy J., 44(1):35-48.

Tahir NA, Majeed HO, Azeez HA, Omer DA, Faraj JM and Palani WRM. 2020. Allelopathic Plants: 27. Moringa species. Allelopathy J., 50(1):35-46.

Vongsak B, Sithisarn P, Mangmool S, Thongpraditchote S, Wongkrajang Y and Gritsanapan W. 2013. Maximizing total phenolics, total flavonoids contents and antioxidant activity of Moringa oleifera leaf extract by the appropriate extraction method. Ind Crops Prod.., 44:566-571.

Wang Y, Gao Y, Ding H, Liu S, Han X, Gui J and Liu D. 2017. Subcritical ethanol extraction of flavonoids from Moringa oleifera leaf and evaluation of antioxidant activity. Food chem., 218:152158.

Zhang H and Ma ZF. 2018. Phytochemical and pharmacological properties of Capparis spinosa as a medicinal plant. Nutrients., 10(2):116. 